\title{
Kosmologi Hindu Dalam Teks Ganapati Tattwa
}

\author{
Ida Bagus Putu Adnyana \\ Universitas Hindu Negeri I Gusti Bagus Sugriwa Denpasar \\ idaadnyana07@gmail.com
}

\author{
Riwayat Jurnal \\ Artikel diterima: 28 Pebruari 2021 \\ Artikel direvisi: 8 Juni 2021 \\ Artikel disetujui: 23 Juni 2021
}

Kata Kunci:

Kosmologi Hindu

Ganapati Tattwa

\section{Keyword:}

Hindu Cosmology

Ganapati Tattwa

\begin{abstract}
Abstrak
Ganapati Tattwa merupakan salah satu teks yang membahas secara gamblang perihal ajaran tattwa yang bernuansa siwaistik. Seluruh ajaran yang terdapat dalam teks Ganapati Tattwa disajikan dalam bentuk dialogis antara Dewa Siwa dengan putranya Sang Hyang Ganapati. Sang Hyang Ganapati mengajukan begitu banyak pertanyaan kepada Dewa Siwa tentang hakikat alam semesta, hakikat manusia, ajaran yoga, kelepasan, dan lain sebagainya yang dijawab dengan bijaksana oleh Dewa Siwa. Ganapati Tattwa menjelaskan konsep Kosmologi Hindu secara jelas tidak hanya dalam tataran penciptaan akan tetapi sampai pada tataran pemeliharaan, peleburan dan bahkan sampai pada proses penciptaan kembali alam semesta. Hal ini yang menyebabkan Kosmologi Hindu dalam teks Ganapati Tattwa berbeda dengan ajaran kosmologi dalam teks lainnya yang belum tentu membahas secara menyeluruh konsep Kosmologi Hindu. Kosmologi Hindu dalam teks ini dijelaskan berawal dari Om-kara yang kemudian melahirkan Windu dan berakhir pada pembentukan alam semesta melalui unsur-unusr Panca Maha Bhuta. Selanjutnya akan mengalami pemeliharaan yang diakomodir oleh unsur-unsur Panca Daiwatma, kemudian dilanjutkan dengan peleburan sampai pada konsep Niskala. Pada akhirnya, alam semesta akan mengalami penciptaan kembali dari konsep Niskala akan melahirkan Om-kara kembali sebagai cikal bakal penciptaan alam semesta.

\section{Abstract}

Ganapati Tattwa is one of the texts that discusses clearly about the teachings of tattwa with Shivaistic nuances. All the teachings contained in the Ganapati Tattwa text are presented in the form of a dialogue between Lord Shiva and his son Sang Hyang Ganapati. Sang Hyang Ganapati asked Lord Shiva so many questions about the nature of the universe, human nature, yoga teachings, liberation, and so on which
\end{abstract}




\begin{tabular}{|l|l|}
\hline Lord Shiva answered wisely. Ganapati Tattwa explains the concept of \\
Hindu Cosmology clearly not only at the level of creation but also at the \\
level of maintenance, dissolution and even the process of re-creating the \\
universe. This is what causes Hindu cosmology in the Ganapati Tattwa \\
text to be different from the teachings of cosmology in other texts which \\
do not necessarily fully discuss the concept of Hindu cosmology. Hindu \\
cosmology in this text is explained starting from Om-kara which then \\
gave birth to Windu and ended in the formation of the universe through \\
the elements of the Panca Maha Bhuta. Furthermore, it will undergo \\
maintenance which is accommodated by the elements of Panca \\
Daiwatma, then proceed with fusion until the concept of Niskala. In the \\
end, the universe will experience a re-creation from the concept of \\
Niskala which will give birth to Om-kara again as the forerunner of the \\
creation of the universe.
\end{tabular}

\section{Pendahuluan}

Alam semesta merupakan tempat yang sangat luas dan tak seorang pun mengetahui dimana ujungnya dan bagaimana rupanya yang sesungguhnya. Terdapat bergitu banyak galaksi yang bertaburan di alam semesta. Menjadi sebuah rahasia umum ketika banyak manusia begitu kagum dengan alam semesta yang maha luas ini meski tak sekalipun pernah melihat isi keseluruhannya. Hanya sedikit bagian saja yang diketahui manusia sudah membuatnya begitu takjub dan kagum. Taburan berjuta hingga bermiliar bintang pada malam hari menambah kekaguman manusia dan menggugah kuriositas-nya untuk dapat menjamah dan mengetahui lebih dalam isi dari dalam semesta. Hal serupa juga disampaikan oleh (Sagan, 1997) sebagai berikut:

Dari suatu tempat yang menguntungkan di ruang antar galaksi, kita akan melihat, bertebaran seperti buih laut pada gelombang ruang angkasa, tak terhitung banyaknya sulur cahaya yang mengutas dan lemah. Ini adalah galaksi-galaksi. sebagian merupakan pengembara yang terpencil; kebanyakan berisi gugus-gugus komunal, berkelompok bersama, mengalir tak berakhir dalam kegelapan kosmik raya.

Ada beberapa ratus miliar $\left(10^{11}\right)$ galaksi, masing-masing dengan rata-rata seratus miliar bintang. Dalam semua galaksi itu, mungkin ada planet sebanyak bintang, $10^{11} \mathrm{x}$ $10^{11}: 10^{22}$, sepuluh miliar triliun.

Rasa ingin tahu yang begitu tinggi membuat manusia berupaya sekeras mungkin untuk menciptakan berbagai teknologi lewat pengetahuan yang terus berevolusi dari sumber utamanya yaitu filsafat "The Mother of Sains". Pertanyaan-pertanyaan mendasar tetapi filosofis mulai menyelimuti cara berpikir manusia seperti: Ada apa di atas sana? Mengapa begitu banyak bintang? Seberapa luasnya? Apa saja yang ada disana selain bintang dan bulan? Siapa yang menciptakan ini semua? Bagiaman Ia menciptakan? Berapa lama Ia menciptakan? Sebelum 
ada semua ini, dulunya apa? Ini merupakan beberapa pertanyaan yang muncul di benak manusia yang haus akan pengetahuan tentang banyaknya misteri di alam semesta. Banyak ilmuan yang mencoba menjabarkan alam semesta lewat berbagai pemikirannya yang dituangkan ke dalam sebuah teori guna merepresentasikan alam semesta.

Salah satu ilmuan yang paling terkenal dan teorinya masih digunakan sampai sekarang adalah George Lemaitre dengan teorinya yang berjudul Big Bang. Teori yang dikemukan oleh George Lemaitre pada tahun 1927 ini awalnya bernama "Hipotesis Primeval Atom". Menurut teori ini alam semesta pada awalnya berada dalam keadaan sangat panas dan padat seperti thermo reactor nuklir. Tiba-tiba dengan alasan yang tidak begitu jelas keadaan panas dan padat, alam semesta mulai berkembang pesat setelah ledakan atau "Big Bang” sekitar 13,7 juta tahun yang lalu dan terus berkembang hinga saat ini (Gupta, 2017).

Pada hakikatnya alam semesta merupakan ruang yang begitu luas dan hampa serta kosong. Kehidupan manusia di bumi sebenarnya diliputi oleh ruang kosong ini dan bumi serta manusia dan seluruh makhluk hidup yang ada di dalamnya hanya sebagian kecil dari keseluruhan isi alam semesta. Disadari atau tidak, kita selalu dikelilingi oleh ruang dan 99\% dari alam semesta terdiri dari ruang kosong. Ruang adalah yang paling halus dari semua eksistensi fisik. Mengingat sifatnya yang sangat halus, misteri ruang masih menjadi tantangan bagi komunitas ilmiah sampai saat ini, meskipun kemajuan ilmu modern berkembang pesat (Gupta, 2017). Teknologi merupakan hasil dari aplikasi ilmu modern yang digunakan manusia untuk membedah dan menganalisa isi dari dalam semesta. Akan tetapi teknologi belum dapat sepenuhnya membantu manusia dalam menjawab seluruh pertanyaan tentang alam semesta.

Manusia terus berupaya untuk menggali pengetahuan yang dapat merepresentasikan alam semesta sehingga lahirlah sebuah disiplin ilmu yang disebut kosmologi. Kosmologi merupakan disiplin ilmu yang secara spesifik membahas tentang alam semesta. Kosmologi merupakan derivat dari ilmu filsafat, sebagaimana karakter atau sifat dari ilmu filsafat yang merupakan sumber dari semua ilmu pengetahuan, maka demikian juga kosmologi memiliki keterkaitan dengan berbagai bidang ilmu pengetahuan (Donder, 2007). Kosmologi berasal dari kata cosmology yang terdiri dari dua kata, yaitu dari kata cosmos, dan kata logy, kata cosmos berarti jagat raya atau alam semesta, dan kata logy berarti ilmu pengetahuan. Jadi Kosmologi adalah ilmu pengetahuan tentang alam semesta (Donder, 2007). 
Kosmologi dalam pandangan filsafat Hindu memberikan penjelasan tentang proses terjadinya alam semesta didasarkan pada kepercayaan akan entitas besar yang menyelimuti alam semesta, yaitu Tuhan. Sehingga kosmologi memiliki ruang tersendiri dalam pandangan Hindu yang disebut dengan istilah Kosmologi Hindu. Dalam Kosmologi Hindu peran Tuhan sebagai causa prima tidak dapat dilepaskan dari seluruh proses penciptaa hingga peleburan alam semesta (Donder, 2007). Akan tetapi menurut (Donder, 2007) dalam bukunya yang berjudul "Kosmologi Hindu Penciptaan, Pemeliharaan, dan Peleburan Serta Penciptaan Kembali Alam Semesta" menyatakan bahwa berbeda dengan kosmologi yang umum dipelajari oleh ilmuan barat, Kosmologi Hindu menempatkan Tuhan pada posisi pertama dan utama sebagai causa prima, "cikal-bakal" (sangkan paraning dumadi) dari alam semesta ini. Kosmologi Hindu melihat penciptaan alam semesta atau jagat raya ini bermula dari Tuhan. Dari dalam badan atau kandungan tuhan (hiranya garbha) alam semesta ini dilahirkan, dan kemudian ke dalam kandungan tuhan (hiranya garbha) pula alam semesta ini akan dikembalikan.

Jika ditelusuri secara seksama dan menyeluruh terdapat banyak ajaran kosmologi yang tertuang ke dalam teks-teks suci Sruti dan Smrti. Masyarakat Hindu di Indonesia dan Bali khususnya mempercayai kitab-kitab agama (Nibandha) sebagai rujukan kehidupan beragama sehari-hari. Kitab-kitab agama tersebut disebut dengan nama lontar. Sebagaimana yang dikatakan oleh (Ambarnuari, 2016) bahwa kitab-kitab agama yang digunakan masyarakat Hindu di Indonesia yakni dikenal dengan lontar, lontar-lontar ini tersebar di seluruh Nusantara, dan beberapa di antaranya masih tersimpan dan dilestarikan oleh umat Hindu di pulau Bali.

Salah satu lontar yang ada di Bali dan kental akan ajaran Kosmologi Hindu adalah lontar Ganapati Tattwa. Lontar Ganapati Tattwa ini telah di alih aksarakan dan di alih bahasakan ke dalam bahasa Kawi dan diterjemahkan ke dalam Bahasa Indonesia oleh Pusat Dokumentasi Dinas Kebudayaan Provinsi Bali. Penelitian ini berupaya untuk menganalisis secara mendalam bagaimana ajaran Kosmologi Hindu dalam teks Ganapati Tattwa yang terkonstruk dalam beberapa pembahasan tentang proses penciptaan, pemeliharaan dan peleburan serta penciptaan kembali alam semesta berdasarkan pada perspektif teks Ganapati Tattwa dan literatur Kehinduan lainnya. Selain itu ajaran Kosmologi Hindu juga terdapat dalam beberapa lontar lainnya seperti Bhuwana Kosa, Adi Parwa, dan Tattwa Jñana. 
Ajaran Kosmologi Hindu dalam lontar Bhuwana Kosa, dijelaskan dengan menggunakan konsep Tattwa Rudra. Tattwa Rudra terjadi dari Śiwa sebagai realitas tertinggi, lalu bersatu dengan Rudra menjadi Purusa, dari Purusa lahir Awyakta, dari awyakta lahir Buddhi, dari Buddhi (sebagai simbol dari sattwam) lahir Ahamkara/Ahangkara (simbol rajas), kemudian lahir Panca Tan Matra sebagai simbol tamas, manah (pikiran) dan Panca Maha Bhuta (Sena, 2017).

Selanjutnya dalam lontar Ādi Parwa, dijelaskan bahwa ajaran Kosmologi Hindu dimulai dari alam semesta yang kosong (sunya). Alam semesta yang kosong (sunya) bertemu dengan Śangkara (Śiwa) dengan Pārwatī. Dari pertemuan itu lahirlah alam semesta. Ajaran Kosmologi Hindu yang terdapat dalam lontar ini diceritakan dalam proses perputaran Gunung Māndara. Gunung Māndara keluar dari minyak, Ardhacandra, Dewi Sri, Dewi Lakshmi, kuda Uchchaihshravas, Kastubhami, dan Amrta (Saitya, 2019).

Kemudian yang terakhir adalah ajaran Kosmologi Hindu yang terdapat dalam lontar Tattwa Jñana dimulai dengan Cetana (elemen kesadaran) dan Acetanan (elemen ketidaksadaran), berikut merupakan ulasan ajaran Kosmologi Hindu dalam lontar Tattwa Jñana:

Cetana (elemen kesadaran) dan Acetanan (elemen ketidaksadaran) yang bersumber dari Bhatara Siwa dan merupakan elemen Siwa Tattwa dan Maya Tattwa. Brahman ingin melihat benda yang diciptakan oleh-Nya menjadi nyata, maka Sang Hyang Atma diberikan untuk dipenuhi dengan Pradhana Tattwa. Pertemuan ini menghasilkan Purusa dan Pradhana yang pada akhirnya Purusa dan Pradhana bertemu kemudian lahirlah Citta yang merupakan simbol dari bentuk kasar Purusa. Kemudian setelah Citta, Guna lahir, sebagai simbol Pradhana Tattwa yang diberikan kesadaran oleh Purusa. Kemudian dari pertemuan Tri Guna dengan Citta maka lahirlah Buddhi. Buddhi merupakan simbol dari pikiran, sebagai bentuk kasar Tri Guna yang diberikan kesadaran oleh Citta. Buddhi melahirkan Ahangkara/Ahamkara. Ahangkara adalah penyebab munculnya Panca Tan Matra. Panca Tan Matra melahirkan Panca Maha Bhuta (Sena, 2019).

Ketiga lontar di atas menjabarkan ajaran Kosmologi Hindu secara umum dan sebatas menjelaskan dari unsur yang paling halus hingga menuju unsur yang paling kasar. Tidak 
dijabarkan secara spesifik ciptaan yang dihasilkan dari proses Virat Vidyā yang terjadi, seperti ciptaan yang paling kecil berupa objek hidup dan sebagainya. Hal ini berbeda dengan ajaran Kosmologi Hindu yang dijabarkan dalam teks Ganapati Tattwa. Ajaran Kosmologi Hindu yang dijelaskan dalam teks ini tidak hanya menjelaskan proses kosmologi dari unsur yang paling halus hingga pada unsur yang paling kasar, akan tetapi lebih menggambarkan hasil ciptaan sampai pada yang paling kecil dan kompleks. Sangat jarang sekali ditemui teks atau lontar seperti teks Ganapati Tattwa ini, yang menjabarkan ajaran Kosmologi Hindu secara rinci dan sistematis. Kebanyakan hanya menjelaskan secara umum dan berhenti pada tataran konsep pembentuk ciptaan tanpa diteruskan hingga pada tataran dimensi ciptaan berupa objek yang hidup dan mengisi kehidupan di alam semesta. Bedasarkan pada latar belakang dan previous studies di atas maka artikel ini akan berusaha membahas tentang ajaran Kosmologi Hindu yang terdapat dalam teks Ganapati Tattwa guna menambah wawasan, referensi, dan khazanah pengetahuan peneliti serta pembaca sehingga dapat berguna bagi masyarakat dan ilmuan Hindu serta berimplikasi pada masa depan pengetahuan Hindu mendatang.

\section{Metode}

Metode penelitian yang digunakan dalam penelitian ini adalah metode penelitian kualitatif deskriptif. Dimana data-data atau informasi yang didapat akan dituangkan ke dalam bentuk narasi dengan menggunakan bahasa Indonesia yang formal dan sesuai dengan EYD. Data-data dalam penelitian ini terbagi atas data primer dan data sekunder. Data primer dalam penelitian ini adalah teks Ganapati Tattwa sedangkan data sekunder dalam penelitian ini adalah buku dan jurnal yang berkaitan erat dengan objek kajian penelitian ini.

Seluruh data dalam penelitian ini diperoleh melalui studi kepustakaan dan dokumen untuk kemudian dianalisis dengan menggunakan metode analisis data dari Miles dan Huberman, dimana aktivitas dalam analisis data kualitatif dilakukan secara interaktif dan berlangsung secara terus menerus sampai tuntas, sehingga datanya sudah jenuh (Sugiyono, 2019). Sedangkan berkaitan dengan instrumen penelitian menurut (Sugiyono, 2019) merupakan suatu alat yang digunakan mengukur fenomena alam maupun sosial yang diamati. Instrumen penelitian yang digunakan dalam pengumpualan data penelitian ini adalah alat tulis, laptop, serta buku-buku penunjang penelitian.

\section{Landasan Teori}

Teori yang digunakan dalam penelitian ini adalah teori Hermeneutika dari Josef Bleicher. Hermeneutika merupakan sebuah teori yang berupaya untuk merepresentasikan 
makna berdasarkan pada kajian filsafat. Teori Hermeneutika Josef Bleicher menjelaskan bahwa:

Hermeneutika dapat di definisikan secara longgar sebagai suatu teori atau filsafat interpretasi makna. Baru-baru ini Hermeneutika telah muncul sebagai topik dalam filsafat ilmu-ilmu sosial, filsafat seni dan bahasa, dan dalam kritik sastra meski asalusul modernnya bermula dari awal abad sembilan belas. Kesadaran bahwa ekspresiekspresi manusia berisi sebuah komponen penuh makna, yang harus disadari sedemikian rupa oleh subjek dan yang diubah menjadi sistem nilai dan maknanya sendiri, telah memunculkan 'persoalan-persoalan Hermeneutika': bagaimana proses ini memungkinkan untuk dilakukan dan bagaimana mengubah makna yang dimaksudkan secara subjektif menjadi objektif berdasarkan kenyataan bahwa mereka dimediasikan oleh subjektivitas interpretator sendiri. Hermeneutika kontemporer dicirikan oleh pandangan-pandangan yang dipenuhi dengan perdebatan mengenai persoalanpersoalan ini, yang dapat dibagi menjadi tiga bidang yang jelas-jelas terpisah, yaitu: Teori Hermeneutis, Filsafat Hermeneutik, dan Hermeneutika kritis. Teori Hermeneutika memusatkan diri pada persoalan teori umum interpretasi sebagai metodelogi bagi ilmu-ilmu humaniora (atau Geisteswissenchaften, termasuk juga didalamnya ilmu-ilmu manusia). Melalui analisis atas verstehen sebagai metode yang cocok untuk mengalami kembali atau berpikir kembali atas apakah yang sesungguhnya dirasakan atau dipikirkan oleh pengarang (Bleincher, 2007).

Teks Ganapati Tattwa ditulis dengan menggunakan bahasa kawi yang menyebabkan tidak semua orang dapat memahami arti dan maknanya. Oleh sebab itu, peneliti berupaya untuk merepresentasikan makna dari teks ini menggunakan teori Hermeneutika agar mudah dipahami oleh pembaca nantinya sebagai upaya untuk menambah khazanah pengetahuan pembaca dan juga peneliti. Hal ini sesuai dengan prinsip kerja teori Hermeneutika yang berupaya untuk memberikan penafsiran terhadap isi teks sehingga dapat memperoleh makna yang terkandung dalam tek tersebut. Maka dari itu, teori Hermeneutika sangat cocok untuk membahas konsep penciptaan, pemeliharaan, dan peleburan serta penciptaan kembali alam semesta dalam teks Ganapati Tattwa sebagai hasil dari interpretasi makna terhadap teks tersebut.

\section{Pembahasan}

\section{Gambaran Umum Teks Ganapati Tattwa}

Teks Ganapati Tattwa adalah sebuah lontar yang memiliki nuansa ajaran tattwa atau Ketuhanan. Ganapati Tattwa merupakan teks yang bersifat siwaistik dengan tokoh utamanya yaitu Dewa Siwa dan Sang Hyang Ganapati (Laksmi, dkk. 2018). Lontar ini berisi percakapan antara Ganapati dengan Dewa Siwa. Ganapati adalah putra dari Dewa Siwa dan merupakan dewa penanya yang sangat cerdas. Dewa Siwa adalah Maheswara, yang menjelaskan sekaligus mereinterpretasikan mengenai seluk beluk alam semesta atau jagat raya beserta isinya. 
Terutama bagi umat Hindu yang memiliki tujuan hidup mulia yaitu moksartham jagadhita ya ca iti dharma atau mencapai jagadhita (kesejahteraan jasmani) dan moksa (ketentraman batin) (Diantary \& Hartaka, 2020). Teks Ganapati Tattwa di tulis ke dalam 37 lembar daun tal (rontal) dan di susun ke dalam 60 bait dengan menggunakan ulasan berbahasa Kawi. Penjelasan sloka-sloka dalam lontar ini ada yang isinya singkat dan ada juga yang isinya panjang, terutama pada bagian pendahuluan atau permulaan.

Setiap ajaran tentunya memiliki pokok-pokok atau inti sari ajarannya masing-masing, tak terkecuali teks Ganapati Tattwa. Teks yang bercorak filsafat siwaistik ini memiliki pokokpokok ajaran yang tidak jauh berbeda dengan lontar-lontar tattwa lainnya yang ada di Bali seperti Jnanasidhanta, Wrhaspati Tattwa, Bhuwana Kosa, dan yang lainnya. Adapun pokokpokok ajaran yang terdapat dalam teks Ganapati Tattwa menurut (Mirsha, dkk. 1995)sebagai berikut:

Omkara adalah sabda śunya, nada Brahman, asal mula dari mana Panca Daiwātmā: Brahma, Wisnu, Iśwara, Rudra dan Sang Hyang Sadāsíwa di lahirkan. Panca Daiwātmā adalah sumber dari mana Panca Tanmatra di ciptakan. Panca Tanmatra: ganda, unsur bau; rasa, unsur rasa/kenikmatan; rupa, unsur bentuk; sparsa, unsur rabaan; dan sabda, unsur suara adalah sumber dari Panca Mahābhuta: akaśa, ether, bayu, angin; teja, sinar; apah, zat cair, dan perthiwi, zat padat. Dari Panca Mahābhuta inilah alam semesta beserta isinya di ciptakan, dan Sang Hyang Śiwātma menjadi sumber hidup yang menggerakan segala ciptaan-Nya (sloka 1-2, 25-39).

Sadanggayoga: Pratyahārayoga, Dhyānayoga, Pranayāmayoga, Dharanayoga, Tarkkayoga dan Semadhiyoga adalah jalan spiritual untuk mencapai kelepasan, dijelaskan dalam sloka 3-9.

Sloka 10, 18, 19, 22-24 menjelaskan tentang "Padma Hati” sebagai Śiwalingga dimana Beliau harus direnungkan. Hanya ia yang bijaksana, berhati suci dan penuh keyakinan yang dapat mengetahui Beliau. Beliau hendaknya setiap saat dipuja dengan sarana Sang Hyang Caturdasāksara. Sedangkan sloka 11-17 menjelasakan tentang berbagai jenis lingga.

Sloka 20 menerangkan anggapan orang yang bodoh dan sombong tentang ātman.

Sloka 21 menjelaskan stana Bhatara Wisnu, Brahma dan Śiwa pada badan jasmani.

Sloka 40-42 menjelaskan bahwa Sang Hyang Bheda Jnana adalah ajaran rahasia tentang manusia. Yang berhak menerima ajaran rahasia ini adalah ia yang sungguhsungguh melaksanakan dharma.

Sloka 43-55 menjelaskan tentang kelepasan. Ada tiga prilaku orang yang mengutamakan kebebasan dan pengetahuan yang suci adalah sasaran untuk mencapai penyatuan diri dengan Sang Roh Yang Agung.

Sloka 56-59 menjelaskan tentang panglukatan Ganapati. Sarana upakara yang diperlukan, mantra yang mesti dipergunakan dan kegunaan panglukatan tersebut. 
Dan sloka 60 adalah mantra pujaan yang ditujukan kepada Sang Hyang Ganapati dan Saraswati.

Inilah inti ajaran atau pokok-pokok ajaran yang terdapat dalam teks Ganapai Tattwa, yang masing-masing sloka-nya memiliki bahasannya tersendiri. Secara konseptual, teks Ganapati Tattwa pada dasanya memang lebih dominan merujuk pada ajaran kelepasan atau kamokșan, akan tetapi tidak sedikit juga ajaran kosmologi yang terkandung di dalam teks ini, utamanya yang berkaiatn dengan Kosmologi Hindu. Maka dari itu kajian Kosmologi Hindu dalam teks Ganapati Tattwa sangat kompleks sekali dan memiliki keterkaitan dengan lontarlontar tattwa lainnya yang masih satu rumpun.

\section{Konsep Penciptaan Alam Semesta}

Pencipta atau mencipta dalam ajaran agama Hindu dikenal dengan istilah uttpti. Uttpti dalam Kamus Jawa Kuna dapat diartikan sebagai lahir, hasil, asal mula, keuntungan, penghasilan (Zoetmulder, 2006). Dalam kondisi ini Tuhan disebut sebagai uttpti atau yang menciptakan (sebagai asal mula alam semesta). Berkaitan dengan penciptaan (Donder, 2007) menjelaskan bahwa:

Sebagaimana dikisahkan dalam kitab-kitab Purana, Upanisad dan Manu Dharmasastra dan lain-lainnya bahwa keadaan ketika belum ada ciptaan ini demikian sunyi mencekam tidak ada apa-apa dan tidak ada siapa-siapa. Yang ada dalam kekosongan itu hanyalah Tuhan saja, kekosongan itu merupakan sebuah garbha atau kandungan besar bagaikan sebuah kantongan raksasa yang tanpa batas. Di dalam kandungan yang besar itulah terdapat aset Tuhan berupa astaprakrti. Dalam astaprakrti itu terdapat delapan unsur yang terdiri dari; prtivi (tanah), apah (air), nala (api), bayu (udara), akasa (ether), manah (pikiran), buddhi (budi), ahamkara (ego, kehendak). Menyaksikan keadaan kekosongan itu, Tuhan tergerak untuk menciptakan sesuatu. Tujuannya penciptaan itu adalah untuk memecahkan kesunyian yang mencekam itu.

Pendapat serupa juga disampaikan oleh (Gupta, 2017) yang menerangkan bahwa dengan energi eksternal-Nya (Apara Shakti) Brahman menciptakan elemen dasar ini yang dapat dihancurkan dengan ketentuan tertentu. Ether (ruang) diciptakan pertama, kemudian udara diciptakan karena gerakan dalam ruang, gerakan udara menciptakan api, dari panas air muncul, dan dari air akhirnya bumi diciptakan. Konsep penciptaan alam semesta dijelaskan dengan lugas dalam dialog antara Sang Hyang Ganapati dan Dewa Siwa yang kemudian digambarkan lewat teks Ganapati Tattwa, berikut ulasan konsep penciptaan alam semesta dalam teks Ganapati Tattwa. 
Ganapati uwaca, sembah ning tanaya ra sanghulun, hanta mwah warahana ri prakasa ning bhuwana, lamakane wruh ranak rahadyan sanghulun.

(Ganapati Tattwa, 1.3)

Terjemahan:

Ganapati berkata "Sembahnya hamba putra paduka, selanjutnya beritahukanlah lagi perihal awal mula adanya alam semesta ini agar dapat hendaknya hamba putra tuanku mengetahuinya".

(Mirsha, dkk. 1995)

Iswara uwaca, anakku sang Ganapati, mangke pireng wakena pawarah Kami, umajarakena ri katattwan ing bhuwana, saking Pancadaiwatma mijil pancatanmatra, lwirnya sakeng Brahma mijil gandha, sakeng Wisnu mijil rasa, sakeng Rudra mijil rupa, sakeng Kami mijil sparsa, sakeng hyang Sadasiwa mijil sabda, mwah sakeng sabda mijil akasa kayeki rupanyanira ya, warna kadi suddhasphatika.

Sakeng spasra mijil wayu, kayeki rupa nira wi, sweta a warna, sakeng rupa mijil teja, kayeki rupa nira ni, warna sweta, bang, ireng, sakeng rasa mijil apah, kayeki rupa nira omaye, krsna warna nira, sakeng gandha mijil prthiwi, keyeki rupa nira Om, warna pita, nakaraksaranya, sastraning hurip Omkara, mwah anaku sang Ganapati, sakeng prthiwi mijil bhumi, saking apah mijil wai, sakeng teja tang aditya, candra, lintang, sakeng wayu mijil tang angin. sakeng akasa mijil swara, sakeng bhuwana mijil tang sthawara, trna, taru, lata, gulma, twaksara, mwang janggama, pasu, paksi, mina, aghnya, mangkana lwiraning bhuwana.

(Ganapati Tattwa, 1.4)

Terjemahan:

Iswara bersabda, "Putraku Sang Ganapati, kini perhatikanlah pemberitahuanku ini untukmu, hendak menjelaskan mengenai hakikat alam semesta. Dari Panca Daiwātmā lahir Panca Tanmatra, yaitu dari Brahma lahir bau, dari Wisnu muncul unsur kenikmatan, dari Rudra timbul mode/bentuk, dari Daku (Iswara) keluar unsur rabaan, dari Sang Hyang Sadasiwa nada/suara. Lagi pula dari sabda timbul ether, seperti YA ini rupanya, berwarna bagaikan mutiara bening; dari sparsa muncul angin, begini rupanya $W I$, berwarna putih; dari rupa keluar sinar, seperti $N I$ ini modenya, berwarna putih-merah-hitam dari rasa lahir zat cair, berupa begini sebagai $O-M A-Y E$; hitam warnanya, dari gandha timbul tanah, bermode bagaikan $O M$; warna kuning, $N A$ bentuk hurufnya, berkode spiritual OM-kara. Dan lagi putraku Sang Ganapati: dari perthiwi terwujudlah bumi, berkat apah muncul air; karena teja tercipta matahari, bulan dan bintang; oleh karenanya wahyu adalah angin; dari akasa lahirlah bunyi/suara; berkat alam semesta lahirlah tumbuh-tumbuhan (seperti) rumput pohon kayu, tanaman melata, serba kulit-kelopak, dan inti serta segala mahkluk (yaitu) binatang/ternak, burung, ikan, makhluk halus; demikianlah macamnya alam semesta itu.

(Mirsha, dkk. 1995) 
Dari sloka di atas di-ketahui bahwa terdapat dialog antara Sang Hyang Ganapati dengan Dewa Siwa, yang bertanya tentang hakikat alam semesta. Dalam sloka tersebut dijelaskan bahwa alam semesta bermula dari Panca Daiwātmā dan kemudian darinya lahir Panca Tanmatra. Adapun bagian-bagian dari Panca Daiwātmā itu adalah Brahma, Wisnu, Rudra, Daku (Iswara), dan Sang Hyang Sadasiswa, sedangkan Panca Tanmatra bagian-bagiannya yaitu Gandha, Rasa, Rupa, Sparsa, dan Sabda. Keduanya memiliki korelasi yang sangat erat karena pada hakikatnya Panca Tanmatra lahir dari Panca Daiwātmā. Dari Brahma lahir Gandha (bau), dari Wisnu lahir Rasa (kenikmatan), dari Rudra lahir Rupa (mode/bentuk), dari Daku (Iswara) lahir Sparsa (rabaan), dan dari Sang Hyang Sadasiwa lahir Sabda (nada/suara). Setelah itu Panca Tanmatra melahirkan Panca Maha Bhuta yang bagian-bagiannya adalah Akasa, Bayu, Teja, Apah, dan Perthiwi. Dari Sabda lahir Akasa (ether), dari Sparsa lahir Bayu (angin), dari Rupa lahir Teja (sinar), dari Rasa lahir Apah (zat cair), dan dari Gandha lahir Perthiwi (tanah). Lantas dari unsur-unsur atau bagian-bagian Panca Maha Bhuta ini terciptalah bumi, air, matahari, bulan, bintang, angina, bunyi/suara, tumbuh-tumbuhan (rumput pohon kayu, tanaman melata, serba kulit-kelopak), binatang/ternak, burung, ikan, dan makhluk halus.

Nihan pitutur ira Bhatara Siwa, ri sang hyang gana, Sembah ning tanaya ra sanghulun, Bhatara hanta warahana tanaya ra sanghulun, lamakane wruh ri kawijilan ing pancadaiwatma, saking ndi pawijilan ira, ya ta warahana patik sanghulun.

(Ganapati Tattwa, 1.1)

Terjemahan:

Beginilah nasihat-Nya Bhatara Siwa terhadap Sanghyang Gana. "Sembah hamba putra paduka kehadapan Bhatara, tolonglah hendaknya berkati beritahukan hamba putra tuanku, agar supaya dapat mengetahui perihal keadaan-Nya Panca Daiwātmā itu, dari manakah sumber-Nya, itulah hendaknya jelaskan pada hamba putra tuanku!".

(Mirsha, dkk. 1995)

Iswara uwaca, anakku sang Ganapati pirengwakena pawarah Kami ri kita, ikang sabda sunya, sakeng Omkara mijil bindu, kadu embun hana ri agra ning kusa, kasenwan Rawi, mahening kadi dhupa, diptan nira mabhraakara karasakeng bindu matemahan pancadaiwatma, Brahma, Wisnu, Rudra, Kami, mwang sang hyang Sadasiwa, Mangkanaanakku makapawijilan ing Daiwatma.

Terjemahan: 
Iswara bersabda, "Putraku Sang Ganapati, perhatikanlah wejanganku ini untukmu, yakni sabda spiritual (gaib): dari OM-kara muncul Windu, bagaikan embun yang berada di ujung rambut/rumput, disinari matahari bening bagaikan dupa, sinarnya terang cemerlang berkilauan. Dari Windu itu muncullah Panca Daiwātmā, (yaitu) Brahma, Wisnu, Rudra, Kami/Daku, dan Sanghyang Sadasiwa. Demikianlah putraku, perihal keadaanya Daiwātmā itu".

(Mirsha, dkk. 1995)

Sloka di atas merupakan sloka yang menjelaskan tentang asal usul Panca Daiwātmā, yang sebelumnya telah di jelaskan dalam sloka 1.3 dan 1.4. Bhatara Siwa memberikan wejangan kepada Sang Hyang Ganapati bahwa Panca Daiwatma bersumber atau berasal dari Windu yang bersinar terang cemerlang berkilauan dan Windu sendiri muncul sebagai akibat dari OM-kara. Jadi secara konseptual proses terjadinya atau adanya Panca Daiwātmā dapat di jelaskan seperti ini; dari OM-kara lahir atau muncul Windu, dan dari Windu lahir atau muncul Panca Daiwātmā, yang bagian-bagiannya antara lain Brahma, Wisnu, Rudra, Kami/Daku (Iswara), dan Sang Hyang Sadasiwa.

Ganapati uwaca, sembahning tanaya ra sanghulun, apan huwus katamaji sarwa sajnana Bhatara ri katattwan ikang bhuwana, mangke mwah warahana ranak Bhatara, lamakane wruh ri kawijilan ing manusya.

(Ganapati Tattwa, 1.5)

Terjemahan:

Ganapati berkata, "Sembahnya hamba putra paduka, berhubung telah dimengerti segala wejangan pendidikan Bhatara mengenai hakekat alam semesta itu, namun kini beritahukanlah lagi putra paduka Bhatara agar supaya dapat mengetahui perihal penjelmaan (kelahiran) manusia ini".

(Mirsha, dkk. 1995)

Iswara uwaca, anaku sang Ganaraja, tan pahi kawijilan ing manusya, kalawan kawijilaning daiwa, mwang pawetwan ing bhuwana, apan ikang manusya mijil sakeng bindu, mula prathamaning Omkara, apa ta lwirya, Brahma Wisnu makarya sarira, ikang kinarya prtiwi mwang apah, Rudra makarya panon, ikang kinarya teja, Kami akaryoswasa, ikang kinarya sparsa, sanghyang Sadasiwakarya swara, ikang kinaryakasa, mangkanaku lwie ikang atma anjanma.

(Ganapati Tattwa, 1.6)

Terjemahan:

Iswara bersabda, "Putraku Sang Ganapati, tiada berbeda kelahirannya manusia dengan manifestasinya Dewa, beserta dengan penciptaannya alam semesta sebab manusia juga 
lahir dari Windu, awal mulanya OM-kara; bagaimana wujudnya, yakni: Brahma (dan) Wisnu menciptakan badan jasmani, yang terbentuk dari unsur tanah dan zat cair; Rudra menciptakan alat pelihat (mata), yang terwujud dari sinar; Daku (Iswara) membuat pernapasan, yang berbentuk rabaan sentuhan; Sanghyang Sadasiwa menciptakan bunyi/suara, yang terwujud dari unsur ether, demikianlah putraku, jenisnya ātman/jiwa yang menjelma (terwujud) menjadi manusia".

(Mirsha, dkk. 1995)

Penjabaran sloka di atas menjelaskan bahwa pada hakikatnya penciptaan dan kelahiran manusia tidak jauh berbeda dengan penciptaan alam semesta. Hal ini bermakna bahwa penciptaan alam semesta (bhuwana agung) sama dengan penciptaan manusia dan atau makhluk hidup lainnya (bhuwana alit). Sama halnya dengan alam semesta, manusia juga lahir dari Windu, dimana unsur-unsur Panca Daiwātmā dan Panca Maha Bhuta berperan aktif dalam membantu penciptaan manusia ini. Unsur Brahma dan Wisnu menciptakan badan jasmani (tubuh manusia), yang terbentuk dari unsur tanah (perthiwi) dan zat cair (apah). Unsur Rudra menciptakan alat atau indera penglihatan yaitu mata, yang terbentuk dari unsur sinar (teja). Unsur Daku (Iswara) menciptakan pernapasan, yang berbentuk rabaan sentuhan (bayu). Kemudian yang terakhir yaitu Sanghyang Sadasiwa menciptakan bunyi/suara, yang terwujud dari unsur ether (akasa).

\section{Konsep Pemeliharaan Alam Semesta}

Tuhan merupakan pencipta alam semesta beserta isinya dan Beliau juga merupakan pemelihara atas segala ciptaan-Nya. Tuhan masuk dan bersemayam di dalam setiap ciptaannya untuk menjaga dan memelihara keseimbangan kehidupan berbagai makhluk yang Beliau ciptakan. Bumi merupakan salah satu dari sekian banyak ciptaan Tuhan, dan Beliau juga bersemayam di dalamnya, sebagaimana yang dijelaskan dalam Brhad-aranyaka Upanisad, III.7.3, sebagai berikut: "Yah prthivyàm tisthan prthivyà antarah, yam prtivi na veda, yasya prthivi sariram, yah prthivim antaro yamayati, esa ta àtmàntaryàmy amrttah", yang artinya "Dia yang berada di bumi (tanah) ini, dan juga masih di dalam bumi, yang mengendalikan bumi dari dalam bumi, dia adalah atman, pengendali dari dalam yang abadi” (Donder, 2007).

Dalam ajaran agama Hindu, istilah pemeliharaan diidentikan dengan kata stiti. Stiti dalam Kamus Jawa Kuna diartikan sebagai keberlanjutan, keberadaan yang dilanjutkan, peraturan yang telah mantap, kondisi tetap, ikatan-ikatan yang telah tetap, khususnya tentang 
moralitas (Zoetmulder, 2006). Dijelaskan dalam teks Ganapati Tattwa proses pemeliharaan alam semesta yang dilakukan oleh Tuhan dalam hal ini yang dilaksankan oleh Dewa Siwa, adalah sebagai berikut:

Ganapati uwaca, sampun kagraha sapawarah Bhatara, ri kandaning bhuwana mwang manusya, mangke mwah waraha ranak Bhatara, ri sthana ning daiwatma ring sarira, mwang hana ring bhuwana.

(Ganapati Tattwa, 1.7)

Terjemahan:

Ganapati berkata, "Sudah terungkap segala wejangan Bhatara mengenai hal alam semesta beserta manusia itu, kini beritahukanlah lagi putra paduka Bhatara perihal statusnya Daiwātmā itu dalam hubungan badan jasmani dan keadaanya di dunia!".

(Mirsha, dkk. 1995)

Iswara uwaca, kaki anaku sang Ganadhipa, mangke pirengwakena pawarah Kami ri kita, ri kahanan ing daiwatma ring sarira, apan tunggal ikang janma kalawan bhuwana, yajanma, ya bhuwana. Apa ta lwirnyan, yapwan ing bhuwana Brahmakayangan ing daksina, rumkasa bhumi. Wisnu akayangang ing Uttara, rumaksa jala. Rudrakayangan ing pascima, rumaksa Surya, Candra, Lintang. Kami akayangan ing purwa, rumaksa wayu. Sanghyang Sadasiwa akahyangan ing madhya rumaksakasa, mwah yapwan ing jadma, Brahma mangasthana ring muladhara mangraksa raga, ababahan ring irung, mangulahaken gandha, Wisnu mangasthana ring nabhi, mangraksa sarira, ababahan ring jihwa, mangulahaken rasa, Rudra mangasthana ring hati, mangraksa jagra, ababahan ring tingal, mangulahaken idep, Kami mangasthana ring kantha, mangraksaturu, ababahan ring kutuk, mangulahaken sabda, sang hyang Sadasiwa mangasthana ring jihwagra, mangraksa sarwajnana, ababahan ring karna, mangulahaken swara. Mangkana lwirning Daiwatma ring sarira mwah ring bhuwanagung.

(Ganapati Tattwa, 1.8)

Terjemahan:

Iswara bersabda, "Duhai putraku Sang Ganapati, kini perhatikanlah penjelasanku padamu, dalam hal status/keadaannya Daiwātmā pada tubuh jasmani; sebab tunggal juga adanya manusia itu dengan alam semesta ia manusia diapun juga alam semesta.

Bagaiamana sih halnya, yakni: adapun pada alam semesta Brahma berstatus di selatan, memilihara tanah/bumi; Wisnu berstatus di utara memelihara zat cair/air; Rudra berstatus di barat, mengendalikan matahari, bulan dan bintang; Daku (Iswara) berstatus di timur mengatur udara/angin; Sanghyang Sadasiwa berstatus di tengah, memelihara etherlatmosphere. Dan kalau dalam tubuh manusia, Brahma berstutus di muladhara, menghidupkan indra/jasmaniah, berhubungan dengan hidung, memerlukan bau; Wisnu berstatus di pusat/nawe, memelihara badan jasmani, berhungan dengan lidah, memerlukan unsur kepuasan (rasa); Rudra berstatus di hati, mengatur kesadaran/tekad, 
berhubungan dengan pandangan mata, menentukan pikiran; Daku (Iswara) berstatus di kerongkongan/throot, mengendalikan ketiduran, berhubungan pada mulut, mengatur nada/suara; Sanghyang Sadasiwa berstautus di ujung lidah, menguasai segala pengetahuan, berhubungan dengan telinga, meneliti keadaan suara. Demikianlah statusnya Daiwātmā itu masing-masing dalam tubuh jasmani dan pada alam semesta.

(Mirsha, dkk. 1995)

Dari sloka di atas dapat direpresentasikan bahwa setelah Dewa Siwa menjelaskan kepada Sang Hyang Ganapati terkait dengan hakikat alam semesta dan manusia, maka kini Dewa Siwa akan menjelaskan tentang bagiaman status Panca Daiwātmā dan keadaanya di dunia setalah proses penciptaan selesai. Secara tidak langsung sloka ini akan menjabarkan bagaimana konsep pemeliharaan alam semesta setelah terjadinya penciptaan. Sloka di atas menjelaskan bahwa manusia dan alam semesta pada hakikatnya tunggal karena keduanya dilahirkan dari satu sumber yang sama. Unsur-unsur Panca Daiwātmā memiliki tugas untuk memilihara alam semesta beserta dengan isinya. Brahma berada di selatan berfungsi untuk memilihara tanah/bumi, Wisnu berada di utara berfungsi untuk memelihara zat cair/air, Rudra berada di barat berfungsi untuk mengendalikan matahari, bulan dan bintang, Daku (Iswara) berada di timur berfungsi untuk mengatur udara/angin, dan Sanghyang Sadasiwa bersada di tengah berfungsi untuk memelihara ether/atmosphere. Inilah tata letak arah dan fungsi pemeliharaan Panca Daiwātmā di dunia atau alam semesta (bhuwana agung).

Sedangkan jika dalam tubuh manusia (bhuwana alit), Brahma berada di muladhara berfungsi untuk menghidupkan indra/jasmaniah yang berhubungan dengan bau, yaitu hidung. Wisnu berada di pusat/nawe berfungsi untuk memelihara badan jasmani yang berhungan dengan unsur kepuasan (rasa), yaitu lidah. Rudra berada di hati berfungsi untuk mengatur kesadaran/tekad yang berhubungan dengan pikiran. Dakiu (Iswara) berada di kerongkongan berfungsi untuk mengendalikan tidur yang berhubungan dengan mulut serta mengatur nada/suara. Selanjutnya yang terakhir adalah Sanghyang Sadasiwa berada di ujung lidah yang menguasai segala pengetahuan, berhubungan dengan telinga serta meneliti keadaan suara.

\section{Konsep Peleburan dan Penciptaan Kembali Alam Semesta}

Menjadi sebuah hal yang tidak dapat dihindari bahwa setiap yang hidup pasti akan mati. Ini merupakan kodrat mutlak dan hukum alam yang tidak seorang pun dapat menghindarinya. Hal ini juga berlaku bagi alam semesta, meskipun alam semesta sangat luas tak terhingga, ia 
akan tetap hancur dan hilang pada akhirnya. Menurut (Supartha, 2020), alam semesta tidak hanya mengalami penciptaan, namun juga mengalami peleburan. Peleburan merupakan salah satu wujud kasih sayang Tuhan kepada seluruh ciptaannya. Peleburan tidaklah terjadi hanya pada alam semesta namun, peleburan juga terjadi pada manusia. Peleburan pada manusia dikenal dengan sebuah istilah yaitu pralaya, sedangkan peleburan alam semesta ini dikenal dengan mahapralaya.

Pada hakikatnya penciptaan selalu berdampingan dengan peleburan dan keduanya saling berkaitan. Banyak manusia yang mengatakan bahwa peleburan merupakan wujud kemurkaan Tuhan, tetapi sebanarnya peleburan merupakan wujud cinta kasih Tuhan kepada makhluk ciptaannya sama seperti ketika Tuhan menciptakan alam semesta beserta isinya.

Penciptaan yang di dalamnya juga terkadung peleburan adalah wujud cinta kasih tuhan. Manusia sangat mudah memahami jika penciptaan itu sebagai wujud cinta kasih Tuhan. Tetapi sebaliknya manusia sangat sulit untuk memahami bahwa peleburan atau kematian itu sebagai wujud kasih sayang Tuhan. Satu di antara seribu belum tentu ada orang yang dapat memahami bahwa kematian itu adalah wujud dari kasih sayang Tuhan. Sri Arjuna saja yang termasuk manusia unggul dengan kecerdasan rohani yang tinggi, namun tidak bisa memahami kematian sebagai wujud kasih sayang Tuhan (Donder, 2007).

Peleburan atau dalam ajaran agama Hindu disebut pralina dalam Kamus Jawa Kuna diartikan sebagai larut, hilang, padam, habis, mati (Zoetmulder, 2006). Konsep peleburan alam semesta juga dijelaskan dalam teks Ganapati Tattwa, yang digambarkan melalui dialog antara Dewa Siwa dengan Sang Hyang Ganapati. Berikut merupakan ulasan percakapan antara keduanya yang membahas tentang peleburan alam semesta.

Ganapati uwaca, sembahning tanaya ra sanghulun, hana warahana ranak Bhatara ri hilang nikaneng urip, maring henti paranya, ya tika waraha patik Bhatara.

(Ganapati Tattwa, 1. 16)

Terjemahan:

Ganapati berkata, "Sembahnya hamba putra tuanku, ada lagi beritahukanlah hendaknya putra paduka Bhatara mengenai keadaan hilangnya hidup itu, hingga batas sasarannya yang terakhir, itulah jelaskan pada hamba paduka Bhatara".

(Mirsha, dkk. 1995)

Iswara uwaca, udhuh anaku sang Ganapati, atyanta mahabhara patakwanananta ri Kami, aluhur ndatan pahingan, ajero ndatan katutugan, denta tumakwani guna, mangke den enak pwa kita ng rasanana, Kami apawarahanaku, ilang ning atma, mantuk mareng jiwa, ilang ning anaku, umantuk mareng nirwana, ilang nikang nirwana, mantuk mareng sunya, ilang ning sunya, mantuk mareng suksmarupa, ilang ning sukmarupa, umantuk mareng sang hyang ngamut mnga, sthana nira ring agraning akasa, hilang sang hyang ngamut mnga, mantuk mareng sarining niskala. 
Terjemahan:

Iswara bersabda, "Aduh putraku Sang Ganapati, sungguh sangat hebat pertanyaanmu padaku, menanjak tinggi tiada batasnya, mendalam tanpa tersusulkan, olehmu menanyakan yang bermanfaat, kini hendaknya baik-baiklah olehmu memperhatikannya, Daku memberi penjelasan pada putraku: hilangnya atma kembali ke jiwa, hilangnya jiwa kembali ke nirwana, hilangnya nirwana itu kembali ke Sunya, hilangnya Sunya kembali ke Suksma-rupa, hilangnya Suksma-rupa kembali ke Sanghyang Ngamut-Menga, beristina dipuncak angkasa (ether), hilang Sanghyang Ngamut-Menga kembali ke inti sarinya kegaiban (niskala).

(Mirsha, dkk. 1995)

Ganapati uwaca, sembah ning tanaya ra sanghulun, kayan hupta ranak Bhataratanya, henti ikang ingaranan agraning akasa, sthana nira sang hyang ngamut mnga, hanta waraha patik Bhatara.

(Ganapati Tattwa, 1. 18)

Terjemahan:

Ganapati berkata, "Sembahnya hamba putra paduka, semakin berminat hamba putra Bhatara hendak bertanya, sampai dimana batasnya yang dimaksud dengan puncaknya angkasa/ether, (dan) statusnya Sanghyang Ngamut-Menga, tolonglah hendaknya beritahukan hamba putra Bhatara selanjutnya!".

(Mirsha, dkk. 1995)

Iswara uwaca, udhu kita sang Ganapati, ikang ingaranan agra ning aksa ring lingganada, ya ta babahan tunggal alineb, ngaran babahan purusa, ya ta marganira sang hyang Siwatma, mwah yapwan teka ri kapatyanta hana metu ring puser kadi kukus rupa nira, sang hyang Siwatma sah pwa sira saking puser anuju maring Siwamandala. Siwamandala ngaran ring suka tan pabalik duhkha, hayu tan pabalik hala, tan hana swabhawa nira tkerika, ya Siwaman dala ngaran, mwah hana sang hyang Pancatma nga, lwirnya, atma, paratma, antaratma, niratma, sunyatma, yeka tunggalakena maring Siwatma, sang hyang Siwatma amengkena babahan ning ineb, anuju maring pantara, warna kadi hemas linebur, ya ta dalan rahayu dahat, yekara arah babahan nga, haywa simepang yapwan teka ri patinta, hay wa tan wawa anaku, reh rahasya temen ika.

Terjemahan:

(Ganapati Tattwa, 1. 19)

Iswara bersabda, "Aduh engkau anakku Sang Ganapati, adapun yang dimaksud puncaknya angkasa itu ialah pada Lingga Nada, yaitu hubungan tunggal yang gaib/rahasia, disebut juga koneksi Purusa, itulah perlintasannya Sanghyang Siwatma, 
dan apabila tiba saatnya kamatian itupun ada juga muncul pada pusar/nabi bagaikan asap wujudnya, Sanghyang Siwatma sesudahnya pindah dari pusar/nabi menuju ke Siwamandala (Siwaloka/Alam Siwa), Alam Siwa itu bermakna bahagia tanpa kembali sangsara, baik tiada terbalik buruk, tak ada pengaruh materi hingga disana, itulah yang dimaksud Siwamandala. Dan ada lagi yang disebut Sanghyang Pancatma yaitu: Ätman, Parātman, Antarātman, Nirātman, dan Sunyātman, itu semua bertunggalan pada Siwatma, Sanghyang Siwatma membuka hubungannya pada ubun-ubun, menuju saluran yang patut ditempuh, warnanya bagaikan emas-limbur, itulah saluran yang amat utama, demikianlah yang dimaksud rangkaian sulur koneksi, janganlah keliru, meskipun menjelang tiba ajalmu, jangan ragu anakku, sebab hal itu sangat rahasia".

(Mirsha, dkk. 1995)

Penjelasan pada sloka di atas memberikan gambaran peleburan alam semesta melalui penjelasan peleburan pada kehidupan manusia. Pada pembahasan sloka sebelumnya yaitu sloka 1.8 dijelaskan bahwa manusia dan alam semesta tunggal adanya, karena keduanya sama-sama terlahir dari Windu dan segala proses yang terjadi di antara keduanya adalah sama. Jadi dapat disimpulkan bahwa konsep peleburan pada manusia sama dengan konsep peleburan pada alam semesta. Pada sloka di atas dijelaskan bahwa peleburan terjadi ketika hilangnya àtman atau dalam konsep semesta unsur-unsur pembentuk alam semesta telah hilang dan kembali ke entitas asalnya (jiwa), kemudian Ia kembali ke nirwana, dan nirwana kembali ke sunya. Pada akhirnya sunya akan kembali ke suksma rupa, dan suksma rupa akan kembali ke Sanghyang Ngamut Menga, kemudian Beliau berkedudukan di puncak angkasa atau ether (puncak angkasa yang dimaksud adalah Lingga Nada). Kemudian dalam keadaan tertentu Sanghyang Ngamut Menga akan kembali kepada entitas tertinggi alam semesta sebagai spirit puncak yaitu Tuhan yang Niskala atau Nirguna yang tidak dapat dibayangkan dan dipikirkan kemahakuasaannya.

Inilah yang disebut sebagai peleburan alam semesta dalam teks Ganapati Tattwa. Dalam prosesnya, Hindu menyakini bahwa setiap penciptaan pasti akan ada pemeliharaan di dalamnya dan juga akan ada peleburan atas semua yang diciptakan dan dipelihara. Akan tetapi, Hindu juga mengenal konsep bahwa setiap yang dilebur pasti akan diciptakan kembali, dan konsep ini juga dijelaskan dalam teks Ganapati Tattwa.

Niskalaj jayate nado nadad bindusamudbhavah, bindos candrasamudbhavas candrad visvah punah-punah. Kalinganya, ikang niskalamijalaken nada, sakeng nada ngmijilaken bindu, sakeng bindu ngamijilaken ardhacandra, sakeng ardhacandra ngamijilaken wiswa maluy-waluy laksananya, wiswa ngaran sanghyang Pranawa, sang hyang Pranawa jatinya Omkara.

(Ganapati Tattwa, 2. 25)

Terjemahan: 
Dari Niskala lahir Nada, dari Nada muncul Bindu, dari Bindu lahir bulan (semi), dari bulan itu ada Wisnu/dunia berulang-ulang. Tegasnya, yang Niskala itu melahirka Nada, dari Nada melahirkan Bindu, dari Bindu melahirkan Ardha-candra, dari Ardha-candra melahirkan Wiswalalam semesta, berulang-ulang pelaksanaannya; Wiswa berarti Sanghyang Pranama, Sanghyang Pranawa, sesungguhnya adalah Om-kara.

(Mirsha, dkk. 1995)

Candvrena sahito visvo yojitah saha binduna, nadena samhrtyaikadha Omkarah kirtitah sada. Ikang wiswa masamyoga lawan ardhacandra, mwang bindu lawan nada, ikang Pranawa ardhacandra mwang bindu nada mapisan, matemahan Omkara wekasan.

(Ganapati Tattwa, 2. 26)

Terjemahan:

Wiswa (alam) berpadu dengan Candra (semi bulan), Bindu dan dengan Nada, dari perpaduan itu senantiasa mewujudkan Om-kara. Wiswa itu berpadu dengan Ardhacandra dan Bindu beserta Nada; energi hidup Ardhacandra dan Bindu serta Nada itu menunggal, menjadi Om-kara selanjutnya.

(Mirsha, dkk. 1995)

Visvah praliyate candre candras ca liyate bindau, bindus ca liyate nada ity etat kramalaksanam. Ikang wiswa umet ring ng ardhacandra, ikang ng ardhacandra lina ring bindu, ikang bindu ya ta umet ring riada, nahan ta. laksana ning tattwa. Mwang ikang nada mulih ring niskala, niskala ngaran mayatattwa, pradhana ika makolihan ing riada. Mwah ikang niskala mulih maring sunyahtara, ikang sunyantara mulih maring atyantasunya, makolihan ing niskala. Mwang anaku sang Ganapati, ikang ingaranan utpatti sthiti pralinan sang hyang Pranawa.

(Ganapati Tattwa, 2. 27)

Terjemahan:

Wiswa melekat pada Candra, dan Candra menempel pada Bindu, serta Bindu kembali pada Nada, demikianlah perihal/keadaan aktivitasnya. Wiswa itu bergantungan pada Ardhacandra, Adhacandra itu lebur dalam Bindu, Bindu itulah bergantungan pada Nada, demikianlah halnya ajaran Fisalfat, dan Nada itu kembali ke Niskala. Niskala itu disebut Mayatattwa, itulah Pradhana (materi) pengembalian-nya pada Nada, dan Niskala itu kembali ke Sunyantara, Sunyantara itu kembali ke Atyanta-Sunya, sebagai pengembaliannya Niskala dan Anakku Sang Ganadhipa, adapun yang dimaksud Uttpti (lahir), Stiti (hidup), dan Pralina (lebur) itulah Sanghyang Pranawa.

(Mirsha, dkk. 1995) 
Konsep penciptaan kembali alam semesta dijelaskan secara terperinci pada sloka di atas. Dimulai dari konsep peleburan yang berada pada puncak tertingginya yaitu Niskala, kemudian darinya lahir Nada, dari Nada muncul Bindu, dari Biindu kemudian lahir bulan (semi), dan dari bulan itu ada Wisnu/dunia berulang-ulang. Kesimpulan yang dapat ditarik secara tegas adalah bahwa dari Niskala melahirka Nada, yang selanjutnya dari Nada melahirkan Bindu, dan dari Bindu melahirkan Ardhacandra, serta dari Ardhacandra melahirkan Wiswa/alam semesta, berulang-ulang pelaksanaannya; Wiswa berarti Sanghyang Pranama, Sanghyang Pranawa, sesungguhnya adalah Om-kara.

Om-kara merupakan perpaduan antara Wiswa, Candra, Bindu, dan Nada. Pada hakikatnya Wiswa melekat pada Candra, kemudian Candra melekat pada Bindu, dan pada akhirnya Bindu kembali pada Nada. Konsepnya adalah Bindu sangat bergantung pada Ardhacandra, sementara Ardhacandra lebur dalam Bindu, dan Bindu bergantung pada Nada. Kemudian pada akhhirnya Nada akan kembali ke Niskala. Niskala disebut sebagai Mayatattwa, inilah, yang disebut sebagai Pradhana (materi), yang pengembaliannya nanti adalah pada Nada, sementara Niskala akan kembali ke Sunyantara. Kemudian Sunyantara akan kembali ke Atyantasunya, yang pengembaliannya nanti pada Niskala, dan yang dimaksud sebagai Uttpti (lahir), Stiti (hidup/memelihara), dan Pralina (lebur) adalah Sanghyang Pranawa.

\section{Simpulan}

Konsep Kosmologi Hindu dalam teks Ganapati Tattwa terdiri atas penciptaan (uttpti), pemeliharaan (stiti), dan peleburan (pralina). Penciptaan dimulai dari Om-kara yang melahirkan Windu, dan dari Windu melahirkan Panca Daiwātmā. Sementara setiap unsurunsur atau bagian-bagian Panca Daiwātmā melahirkan unsur-unsur Panca Tanmatra, dan Panca Tanmatra kemudian melahirkan Panca Maha Bhuta.

Pemeliharaan alam semesta terjadi setelah proses penciptaan selesai, dan ini dimulai dari unsur-unsur Panca Daiwātmā yang memiliki tugas untuk memilihara alam semesta beserta dengan isinya. Brahma berada di selatan berfungsi untuk memilihara tanah/bumi, Wisnu berada di utara berfungsi untuk memelihara zat cair/air, Rudra berada di barat berfungsi untuk mengendalikan matahari, bulan dan bintang, Daku (Iswara) berada di timur berfungsi untuk mengatur udara/angin, dan Sanghyang Sadasiwa bersada di tengah berfungsi untuk memelihara etherlatmosphere. Inilah tata letak arah dan fungsi pemeliharaan Panca Daiwātmā di dunia atau alam semesta (bhuwana agung). 
Selanjutnya setelah pemeliharaan maka sebagai sebuah kodrat yang mutlak, setiap yang diciptalan pasti akan dilebur. Maka konsep peleburan yang terjadi bermula dari hilangnya àtman atau dalam konsep semesta unsur-unsur pembentuk alam semesta telah hilang dan kembali ke entitas asalnya (jiwa), kemudian ia kembali ke nirwana, dan nirwana kembali ke sunya. Pada akhirnya sunya akan kembali ke suksma rupa, dan suksma rupa akan kembali ke Sanghyang Ngamut Menga, kemudian Beliau berkedudukan di puncak angkasa atau ether (puncak angkasa yang dimaksud adalah Lingga Nada). Kemudian dalam keadaan tertentu Sanghyang Ngamut Menga akan kembali kepada entitas tertinggi alam semesta sebagai spirit puncak yaitu Tuhan yang Niskala atau Nirguna yang tidak dapat dibayangkan dan dipikirkan kemahakuasaannya.

Setalah dilebur, maka pasti akan ada penciptaan kembali, hal ini dijelaskan dalam teks Ganapati Tattwa bahwa penciptaan kembali berawal dari konsep peleburan yang berada pada puncak tertingginya yaitu Niskala, kemudian darinya lahir Nada, dari Nada melahirkan Bindu, dan dari Bindu melahirkan Ardhacandra, serta dari Ardhacandra melahirkan Wiswa/alam semesta, berulang-ulang pelaksanaannya; Wiswa berarti Sanghyang Pranama, Sanghyang Pranawa, sesungguhnya adalah Om-kara. Om-kara merupakan perpaduan antara Wiswa, Candra, Bindu, dan Nada. Keempatnya merupakan awal pembentukan konsep Uttpti (lahir), Stiti (hidup/memelihara), dan Pralina (lebur) yang disebut sebagai Sanghyang Pranawa.

\section{Daftar Pustaka}

Ambarnuari, Mery. (2016). "Teo-Kosmologi dalam Teks Bhuwana Mahbah". Skripsi. Denpasar: Fakultas Brahma Widya Institut Hindu Dharma Negeri Denpasar.

Bleincher, Josef. (2007). Hermeneutika Kontomporer Hermeneutika sebagai Metode, Filsafat, dan Kritik. Yogyakarta: Fajar Pustaka.

Diantary, Ni Made Yunitha Asri dan I Made Hartaka. (2020). "Implikasi Yoga Marga Terhadap Kesehatan Rohani” dalam Jurnal Yoga dan Kesehatan Volume 3 No. 2 Hal. 152-162. Denpasar: Fakultas Brahma Widya Institut Hindu Dharma Negeri Denpasar.

Donder, I Ketut. (2007). Kosmologi Hindu Penciptaan, Pemeliharaan, Peleburan dan Penciptaan Kembali Alam Semesta. Surabaya: Paramita.

Gupta, Gauri Shankar. (2017). Mengurai Misteri Kehidupan Ilmu Modern dan Kebijaksanaan Kuno. Surabaya: Paramita. 
Laksmi, Ni Luh Gede Eni, dkk. (2018). "Fungsi dan Makna Yoga dalam Ganapati Tattwa" dalam Jurnal Linguistika: Buletin Ilmiah Program Magister Lingusitik Volume 25 No. 48 Hal. 81-88. Denpasar: Universitas Udayana.

Mirsha, I Gusti Ngurah Rai, dkk. (1995). Ganapati Tattwa: Kajian Teks dan Terjemahannya. Denpasar: Upada Sastra.

Sagan, Carl. (1997). Kosmos. Jakarta: Yayasan Obor Indonesia.

Saitya, Ida Bagus Subrahmaniam. (2018). "Virat Vidyā In The Text Ādi Parwa" dalam PROCEDING INTERNATIONAL CONFERENCE ON: Theology, Philosophy and Religion (ICTHEPRES) Institut Hindu Dharma Negeri Denpasar.

Sena, I Gusti Made Widya. (2017). "Konsep Kosmologi Hindu dalam Teks Bhuwana Kosa" dalam Jurnal Kalangwan Volume 7 No. 1 Hal. 44-55. Denpasar: Institut Hindu Dharma Negeri Denpasar.

Sena, I Gusti Made Widya. (2019). "The Concept Of Hindu Cosmology In The Tattwa Jñana Text” dalam Jurnal Vidyottama Sanatana Volume 3 No. 1 Hal. 13-23. Denpasar: Institut Hindu Dharma Negeri Denpasar.

Sugiyono. (2019). Metode Penelitian Kuantitatif, Kualitatif, dan R\&D. Bandung: Alfabeta.

Supartha, I Gede Agus.( 2020). "Tinjauan Kosmologi Dalam Lontar Bhuwana Sangkșépa" dalam Jurnal Genta Hredaya Volume 3 No. 2. Sekolah Tinggi Agama Hindu Negeri Mpu Kuturan Singaraja.

Zoetmulder, P.J. dan S.O. Robson. (2006). Kamus Jawa Kuna-Indonesia. Jakarta: PT. Gramedia Pustaka Utama.

\section{Sumber lainnya:}

Teks Lontar Ganapati Tattwa. Pusat Dokumentasi Dinas Kebudayaan Provinsi Bali. 